\title{
Community Based Health Insurance in India: Prospects and Challenges
}

\author{
Bhaskar Purohit \\ Indian Institute of Public Health, Sardar Patel Institute Campus, Thaltej, India \\ Email: bpurohit@iiphg.org
}

Received 6 April 2014; revised 7 May 2014; accepted 14 May 2014

Copyright (C) 2014 by author and Scientific Research Publishing Inc. This work is licensed under the Creative Commons Attribution International License (CC BY). http://creativecommons.org/licenses/by/4.0/

(c) (i) Open Access

\section{Abstract}

The health inequities remain high in India with government and private health expenditures clearly favoring the rich, urban population and organized sector workers and the Out of Pocket (OOP) spending as high as $\mathbf{8 0 \%}$, afflicting the poor in the worst manner. The focus of the paper is to examine the potential Community Based Health Insurance (CBHI) offers to improve the healthcare access to rural, low-income population and the people in unorganized sector. This is done by drawing empirical evidence from various countries on their experiences of implementing CBHI schemes and its potential for applications to India, problems and challenges faced and the policy and management lessons that may be applicable to India. It can be concluded that CBHI schemes have proved to be effective in reducing the Catastrophic Health Expenditure (CHE) of people. But success of such schemes depends on its design, benefit package it offers, its management, economic and non-economic benefits perceived by enrollees and solidarity among community members. Collaboration of government, NGO's and donor agencies is very crucial in extending coverage; similarly overcoming the mistrust that people have from such schemes and subsidizing the insurance for the many who cannot pay the premiums are important factors for success of CBHI in India. One of the biggest challenges for the health system is to address the piecemeal approach of CBHI schemes in extending health insurance and inability of such schemes to cover a large number of poor and the unorganized sector workers. Also, there is a need for a stronger policy research to demonstrate: 1) how such schemes can create a larger risk pool, 2) how such schemes can enroll a large number of people in the unorganized sector, 3 ) the interaction of CBHI schemes with other financing schemes and its link to the health system.

\section{Keywords}

Community Based Health Insurance, Catastrophic Health Expenditure, Healthcare Financing, Health Equity, India 


\section{Introduction}

A major concern of developing nations is what proportion of GDP should be spent on health. "Although the developing countries account for $90 \%$ of the global disease burden, they only contribute $20 \%$ of total GDP and only 12 percent of all health spending in the world" [1]. Another concern about health spending in many developing countries is very high Out-Of-Pocket Payments (OOP) spending. The OOP spending is the most inequitable way of financing the healthcare that affects the poor worst. Lack of risk pooling and insurance could be argued as the main reasons for health-related impoverishment in developing nations [2].

Hence, during the last decade, mobilization of funds for achieving healthcare goals has received great attention of researchers, policy makers, donor agencies and reformers. For example, the World Health Organization (WHO) released an exclusive World Health Report (WHR) in 2000 on performance of health systems, which focused on financing as one of the important functions to improve health systems performance. Similarly, the WHR-2010 completely focuses on financing and its importance to move countries towards Universal Health Coverage. In one of the papers on health financing, financing has been described so important that an analogy has been drawn where health financing has been compared to Mothers Milk [3]. However this paper argues that money is only as a necessary condition and not as a sufficient condition for better health.

This paper discusses various aspects of Community Based Health Insurance (CBHI). In an effort to do so, empirical evidence is drawn from various countries, including India, on their experiences of implementing CBHI schemes and possible applications to India, problems and challenges faced and the policy and management lessons that may be applicable to India.

\subsection{Review of Literature}

The review considered many studies from and outside India. The review provides a broad and narrative compilation of existing literature and evidence about CBHI.

For literature review, screening of papers based on the title "CBHI" was done. Text search for the word: CHF, CBHI, India, developing countries was done. During the screening, studies from all geographic regions were included. Later screening of abstracts was done. The studies that were not very clearly about CBHI and its impact, management etc. were excluded. Also, most of the editorials, comments or news articles were excluded.

This review is particularly important in order to look at the scope of CBHI in India especially with the advent of Rashtriya Swasthya Bima Yojana (RSBY) and India's commitment to Universal Health Coverage (UHC). Bibliographic database used for literature review was mainly PubMed. Here are the following journals majorly screened for literature review: Health Policy and Planning, Social Science and Medicine, Economic and Political Weekly, Health Policy, Health Affairs and Health Planning and Management. In addition, some of the major reports published by The WHO and The World Bank on the issues of Health Financing were reviewed.

\section{Healthcare Financing in India: A Critical Look}

According to the WHO database on health financing in India for 2004, India spent 5.0\% of Gross Domestic Product (GDP) on health with General Government Health Expenditure (GGHE) 0.9\% of the total GDP and Private Expenditure nearly $4.1 \%$ of the total GDP. The Out-Of-Pocket (OOP) expenditure accounted for $93.8 \%$ of the Total Private Health Expenditure (TPHE) or 3.84\% of the total GDP. Such figures clearly indicate that public health investment has been very low. The PHE in India has declined from 1.3\% in 1990 to $0.9 \%$ as at present [4]. While it is very difficult to estimate the number of people covered under any kind of health insurance in India, it can be said that for the year 2010, not more than $25 \%$ are covered under any kind of insurance. This figure includes the recent initiative of RSBY by Indian government as well as the major state schemes [5] (Table 1).

Some of the issues that make health financing in India an important policy concern are as follows. Firstly, there is only a very small proportion of public financing (20\%) towards the total health spending and this figure is even worse for a few states. Secondly, nearly $90 \%$ of the private spending is Out Of Pocket (OOP) which arguably is the most inequitable forms of financing [6]. Thirdly, the average per person public expenditure on Health in 2004-2005 was Rs. 268 with huge variations existing across states ranging from Rs. 287 in Kerala to 93 in Bihar [7]. Furthermore, there is a huge inequity in utilization of funds and delivery of healthcare system. For instance, funds favor the better-off states and urban people and the delivery of healthcare system favors the organized sector workers, neglecting the ones in the un-organized sector [8]. Lastly, the health system has a responsibility to protect its people from CHE [9]. But the system is not able to prevent many CHEs because 
Table 1. Total population covered under insurance in 2009-2010.

\begin{tabular}{cccc}
\hline Scheme & Type of Insurance & No. of Beneficiaries (in Millions) & \% of Population Covered \\
\hline CGHS & SHI & 3 & $0.25 \%$ \\
ESIS & SHI & 55.4 & $4.50 \%$ \\
RSBY & Government Based & 79.45 & $6.5 \%$ \\
Rajiv Arogya Shri (AP) & Government Based & 70 & $6 \%$ \\
Kalaingnar (TN) (Discontinued) & Government Based & 35 & $3 \%$ \\
Vajpayee Arogayasgree & Government Based & 1.4 & $0.12 \%$ \\
Yeshawani & Government Based & 3 & $0.25 \%$ \\
Private Health Insurance & Private Insurance & 55 & $4.5 \%$ \\
CBHI & CBHI & $7.5 *$ & $0.62 \%$ \\
Total Population Covered & & $\mathbf{3 0 9 . 7 5}$ & $\mathbf{2 5 . 7 5 \%}$ \\
Total Indian Population & & 1210 & \\
\hline
\end{tabular}

Source: Selvaraj S, A critical assessment of existing Health Insurance Models in India: 2011: Planning Commission of India. ${ }^{*}$ The figure of 7.5 million for CBHI has been taken from Trivedi 2010.

higher OOP payments sometimes indicate that they are financed by selling assets, going into debt temporarily or by reducing consumption of necessities. The World Bank 2002 report estimated that a quarter of all Indians fall into poverty as a direct result of medical expenses in the event of hospitalization [9].

Healthcare in India is financed in several ways that include general revenue, Social Health Insurance (SHI), private insurance, private spending mostly through OOP payments, CBHI and a few state/government sponsored schemes like RSBY, Yeshaswini, etc. Such schemes use the principle of CBHI in the sense of voluntary participation but are really not managed by the community. Hence they are called state-sponsored schemes here.

India faces challenges in the way that healthcare should be financed. For example, while government financing is the most equitable way of financing as it separates contributions from utilization, it is not able to raise enough to protect and cover a large population of India because of the Indian government's limited ability to raise revenue due to lower tax base and allocate to health.

Another way to finance healthcare is through implementation of SHI where revenue is collected through payroll taxes. Unfortunately this method has a limitation for a county like India because the majority of workers in India are either self-employed or not in formal employment, leaving no scope for payroll taxes [6]. According to a survey by National Sample Survey Organization (NSSO) in 1999-2000 in India, nearly 40\% of the total population was employed in any form (nearly 397 million). Of this, 92\% or approximately 370 million were employed in the unorganized sector and merely 28 million (8\%) were in the organized sector [10]. The recent data from NSSO indicate that $93 \%$ of India's workforces include the self-employed and employed in unorganized sector. According to the latest NSSO report, there has been a significant increase in the number of casual workers and decline in the number of regular workers from the period of 1999-2000 and 2004-2005 to 2009 and 2010 [11].

Yet another way to cover people is through private insurance. Since nearly $30 \%$ of the Indian population lives Below Poverty Line (BPL), not many people can afford paying for private insurance. Currently, it is only about $4.5 \%$ of the Indian population covered by private insurance [5].

In India, OOP spending remains the major way of health financing. India relies heavily on OOP spending and only $20 \%$ of the total health expenditure comes from general revenue [12]. OOP is a highly regressive [13] and inequitable way of financing healthcare and has been documented as a cause of significant catastrophic spending in India. This can sometimes lead to impoverishment. It is estimated that in India, $25 \%$ of the families in which a family member has cardiovascular disease have catastrophic expenditure and consequently $10 \%$ of these families are pushed into poverty [14]. Currently in India, only 25\% - 26\% of the total population is covered under any kind of health insurance [5]. Also significant proportions of people forgo medical care as they simply can't afford it. "Sick but not seeking care" for financial reasons is a rising category in NSS consumptions expenditure surveys.

Having discussed limitations of various ways to finance healthcare in a county like India, one of the alterna- 
tive ways of extending health coverage is through CBHI. This seems to be the most feasible option when combined with other methods of financing like government spending, RSBY and SHI for covering the poor and near poor and the ones in the informal sector. However, this method has its own limitations and assumptions, which are discussed in the next section.

\section{Community Based Health Insurance}

\subsection{Definition and Underlying Assumptions}

A very broad definition of community financing is "A scheme that requires community members to prepay for health services". In an ideal CBHI model, "Community members pool their resources to share the financial risks of health care, own the scheme and control its management, including the collection of premiums, the payment of health care providers, and the negotiation of the benefits package" [15]. However, most of the CBHI schemes must cover poor and near poor as these are basically low premium low benefit scheme for the poor.

"The CBHI schemes are based on voluntary and collective pooling of health risks and the ownership of schemes is heightened through community participation in scheme design (including setting premiums and benefits) and management. Various forms can be distinguished, based on the mode of resource mobilization” [16].

There are two basic underlying assumptions for CBHI to function. The first is that governments of lower income countries like India do not have sufficient funds or tax revenue to adequately fund the healthcare for poor people. The second assumptions is that poor and near poor including the ones in the unorganized sector spend a significant amount on health care to both public and private providers which often leads to catastrophic spending pushing rural families to poverty line. Therefore, CBHI can be seen as one of the potential ways to extending the health insurance to the rural and low income population [15].

\subsection{Relevance of $\mathrm{CBHI}$}

The importance of CBHI is being greatly recognized as one of the potential ways to extend healthcare and provide protection against CHE to the poor and near poor and the workers in unorganized sector. In fact, CBHI appear particularly appropriate for a nation like India based on the two underlying assumptions. The first is based on providing insurance coverage to people in the unorganized sector and the poor because they have very limited protection from other sources and mostly rely on government services that do not protect them against catastrophic illnesses. The second assumption being that CHFs seem particularly relevant to low-income countries where government revenue is limited and there is currently extensive reliance upon out-of-pocket payment [17]. According to empirical evidence, one of the biggest advantages of using CBHI over user fees is that the use of the former separates time of payment from the time of use of services, which is better suited to rural households due to their seasonal variations of revenue and expenditures [18].

Because poor people lack the resources to pay for health care, they are far more likely than less poor people to avoid going for care or to become indebted or impoverished trying to pay for it. Peters and colleagues estimated that at least $24 \%$ of all Indians admitted to hospital fall below the poverty line because of their admission and that out of pocket spending on hospital care might have raised by two percentage points the proportion of the population in poverty [9].

\subsection{Strength and Positives about Such Schemes}

There is wide evidence available that CBHI schemes are able to reduce the OOP payments and reduce the CHE. For instance, empirical evidence from a study carried out in India indicates that a CBHI schemes reduced the CHE from 35\% (non-insured) to 15\% (insured). However, this was mainly possible due to high prepayment ratio and inclusion of costly inpatient care in benefit package [19]. Evidence from Chin suggest that CBHI been proved to be associated with increased supply of drugs and availability of medical equipments in rural health posts [20]. CBHI schemes also reduce health inequities thereby reducing OOP expenditure. For example, a study conducted in India showed that insured families spent much less OOP as compared to non-insured families, thereby reducing the incidence of CHE to nearly half for insured families [13]. A study conducted by Liu and Hsiao in rural China demonstrated that social capital plays a huge role for people joining a community health financing scheme [20]. 


\subsection{Constraints and Weaknesses of CBHI}

One of the major drawbacks and criticism for CBHIs has been that they have failed to attract and capture large number of people that they are intended to and this has lead to low enrollment rates. Studies done in China bring out reasons for such low enrollment rates. According to them, there is a low demand despite great need for people to join such schemes [20]. This is because CBHIs require some voluntary contribution from its members. However, there are many poor people who cannot even afford minimum premium for the schemes and as a result their needs are not converted into demands [20]. Reaching the poorest of the poor or not is surely a question and there is more literature to this.

According to a study in Burkina Faso, factors that affected enrollment of people were: affordability, distantly located health facility, poor quality of health services that included long waiting times, over prescribing and differential treatment depending on socio economic status of enrollee, lack of health seeking behavior, cultural beliefs and practices [21]. In addition to this, the Burkina Faso study found lack of adequate knowledge and past bad experiences with such schemes as the two main reasons that prevented people's enrollment in such schemes [21]. On the other hand, lack of trust and awareness of the members are other reasons that keep them away from enrolling in such schemes. Some members do not understand pre-existing disease clauses. However, in some cases, people who can afford paying the premiums also do not join such schemes [20]. Research from India indicates that local schemes are more successful in providing health insurance to poor and rural people and attract more people because people have higher trust in such schemes [22].

However, even if the demand is created, it is not necessary that people enroll for the schemes. The main reasons in the past for failure of CBHI schemes have been managerial problems like poor design, mismanagement, lack of oversight mechanisms and corruption [23].

Yet another factor that negatively influences enrollment is that people do not see any health and economic benefits of joining the scheme [20].

Literature also suggests that in some schemes, there was differential utilization of such services favoring people located near health facilities [23]. This essentially means that people who live far from the facilities actually cross-subsidize those who live near to the health facilities.

Similarly literature from India suggests a few weaknesses of CBHI. One of the biggest concerns and challenges faced in implementing CHF is the low enrollment rate and ineffective risk pooling despite the low premium rates [24]. The first factor that prevents such schemes to reach out to masses is the low awareness amongst the members about their membership in such schemes. Furthermore, since many community schemes provide life and health insurance together, in some cases, members have been reported to be only aware about life insurance part of such schemes and not health insurance part [25].

In some cases, despite reimbursements of medical expenses, such schemes are not able to protect its members against CHE resulting from hospital expenses [19]. Although not researched, this may be one of the factors that influence people's willingness to enroll or continue in such schemes.

Indian studies have also reported some management problems in functioning of such schemes. For example, a study in Gujarat, India found huge time lag between hospital discharge and reimbursements (nearly 3 - 4 months). Such time lag was found to be more in rural areas. In their deeper analysis, they found that nearly 55\% of thus time is for receiving the claims, $25 \%$ for panel's decision and $18 \%$ for receiving the payment. The study also reports low submission rates for claims from poor because of difficult claims procedures and poor access to health services [26].

According to a study conducted in India it was concluded that despite willingness demonstrated from rural populations to join and pay for such schemes, factors like socio-economic status and physical accessibility to quality health services influence people's decision to join such schemes. For the same reasons people prefer private health [27].

In some cases, lack of health seeking behaviour is reflected as many people do not seek treatment until their condition is worsened, increasing the cost of care [28]. Moral hazard is another problem faced while implementing CBHIs. There is more use of health services and over prescription of drugs because people rather insurance pay for such services [25].

Studies done in India indicate that there is higher awareness (about various aspects of such schemes) among urban population than rural population. A study at SEWA indicates higher claim rates in urban areas as compared to rural majorly because of high awareness level of the people. 


\subsection{Major Challenges for CBHI}

The CBHI schemes are primarily meant for people in the unorganized sector, rural population and for people who are poor or near poor. For this reason, such schemes have moderate premium rates for moderate coverage. Despite this, CBHI schemes have failed to address the very low enrollment rates and lack of risk pooling for the people in unorganized sector [24]. One of the biggest challenges for CBHI's is to strike a good balance between serving the poor and maintaining the financial sustainability [19]. This is because the risk pooling is not large and premium rates are very moderate. While CBHI's have proved to be effective in reducing CHE, what is also true is that many of the beneficiaries experience CHE in the event of hospitalization (issue of cashless hospitalization). Therefore, designing benefit packages and premiums in a way so that higher coverage can be provided to people so that they do not experience CHE even after reimbursements remains a big challenge for such schemes. What is also important is to see that higher coverage can be provided to people without affecting the principle of equity [19]. Empirical evidence also shows that CBHIs have really struggled in extending coverage to the needy and eligible population is because many such schemes do not cover big population and only cover a small proportion of eligible population. Another challenge for such schemes is to address the issue of adverse selection. In many schemes, the members are insured more against high cost events that do not occur very frequently than the low cost events that occur more frequently. This ultimately raises the cost affecting either the premium rates or benefit package which are not in complete favor of the beneficiaries. One big management challenge for such schemes is to have a better and clear communication and information flow between people who are managing the schemes and the beneficiaries. Better communication has been described as a sufficient condition for poor members to enjoy greater share of scheme benefit [29].

\section{Discussion}

While India spends about 5\% of GDP on healthcare with Indian governments new commitment to spend 1\% of additional GDP in rural areas, nearly $75 \%$ of the population still remains uninsured. Furthermore, every year about $20 \%$ of the people are pushed below the poverty line due to CHE. CBHIs seem to be a more equitable method for expanding insurance coverage to the poor and the informal sector workers due to some of its characteristics like voluntary in nature, community ownership, social capital and management by community. Here are some of the recommendations.

Tapping the unorganized sector workers and poor: Indian CBHIs mostly target the poor population in rural areas. But there is a huge population in informal sector (both urban and rural) that needs to be tapped. While it is true that a proportion of population in informal sector cannot pay the premiums, it is also true that a portion of this population can pay partial premiums which can create better risk pooling and cross subsidization for the very poor. Research suggests that involvement of people from informal sector in such schemes could lead to increase in social welfare and in better enrollment subsidies [30]. Therefore, some regulatory actions at both state and national level are highly recommended that can ensure that people in informal sector including the self-employed workers are part of such schemes as such measures can ensure better risk pooling.

Increased role of government and NGO's: For a better sustainability and implementation of CBHIs, increased government role and responsibility is really vital. In case of India, Panchayati Raj Institution (PRI) can play a huge role in development and sustainability of such schemes. The government and donor agencies can also play a huge role in subsidizing the insurance in such schemes as lot of people cannot even afford the minimum premium or for those who cannot pay full premiums. Similarly NGO's can play an important role in educating people and expanding coverage to people in rural areas and unorganized sector. For this purpose, village structures already in place (called Village Health and Sanitation Committees) can be used. Moreover, external grants and government subsidies are very essential so that very poor can be fully subsidized. The finance thus raised could also be used to provide benefit packages with higher cap to protect people who experience CHE despite reimbursements from such schemes against hospital costs.

Using the already existing network to build credibility and trust: Research indicates that there is an association between joining CBHI schemes and family social capital variables. Many people do not enroll because they do not trust such schemes. Therefore, to build trust, CBHIs must try to increase ownership of local people by involving them in management and implementation of such schemes. Another way to build trust and to reach out to masses is to capitalize on the already strong rapport of existing structures like NGOs, SHGs, Cooperatives and PRIs with the community by their involvement in such schemes. 
Optimal benefit package: Particular attention should be paid on designing the benefit package for the schemes so that it can attract community and people see some health and economic benefit in joining such schemes. Schemes should be made better by improving their design and management as well as increasing the upper limits of benefit packages so as to reduce CHE. CBHIs must make an effort to design benefit package after taking into account suitability of package depending on the population, geographic characteristics and community needs for effective implementation.

Addressing the management issues: The claims procedures under various CBHIs should be simplified and time lag from hospital discharge to reimbursements should be greatly reduced. Such time lag should address the delay caused from beneficiary side, supply side as well as administrative side that increase the time lag. In particular, schemes must try to address the time in receiving the claims, the time panel takes for making decisions and the time for receiving the payment. Schemes must also pay attention to reasons for low submission rates for claims. In order to simplify the claims procedures, cashless facility, like RSBY may be introduced.

Promote equity: In order to promote equity, premiums should not have a flat rate. Rather they should be progressive in nature and should be based on household/individual income and their capacity to pay. This is because all who join such schemes do not have the same income level.

Useful lessons to be learnt from RSBY: Just like RSBY, CBHIs must make an effort to empanel more public hospitals because they have a very strong presence at the grass roots level. Also, empanelling more public providers would bridge the gap between quality of care between private and public hospitals by creating a healthy competition between the two. This may also help addressing the issue of differential utilization as it would increase people's access to government health services.

More focused research: While there is good amount of research on CBHI in India and elsewhere, research should be focused on the following: 1) understanding people's needs and preferences so that benefit package can be tailored to such needs; 2) understand the reasons behind low claim rates and delayed submission for such claims; 3) extent of coverage under such schemes and potential of CBHI schemes to cover the poor, near poor and unorganized sector workers; 4) assessing how CBHI can contribute to overall financing as a whole without narrowing down to individual schemes contributions.

\section{Conclusion}

In conclusion it can be said that there is a great scope for CBHI in India to effectively expand the coverage to the uninsured, especially the ones who are poor and the one in the informal sector. But enrollment of people for such schemes is very challenging, keeping in the mind some of the management and designs issues of such schemes. The biggest challenge for such schemes is to tailor design benefit package to people's needs so that a right balance between equity and efficiency can be achieved. Success of such schemes can be achieved with collaborative efforts from both government and non-government organizations. Finally, research and academic work must focus on studying and addressing the piecemeal approach of such schemes in providing health insurance to the poor. This should be done by establishing collaborative links with the health system and various stakeholders like government, NGO's and other financing schemes.

\section{Authors Contribution}

BP conceived the review, drafted the manuscript, read and approved the final version. BP is the guarantor of the paper.

\section{Competing Interest}

None declared.

\section{Ethical Approval}

Not required.

\section{References}

[1] Gottret, P. and Scheiber, G. (2006) Health Financing Revisited: A Practitioner's Guide. The World Bank, Washington DC. http://dx.doi.org/10.1596/978-0-8213-6585-4 
[2] WHO (2000) Who Pays for the Health System? The World Health Report 2000, WHO, Geneva.

[3] Hsiao, W. (2007) Why Is a Systematic View of Health Financing Necessary? Health Affairs, 26, 950-961. http://dx.doi.org/10.1377/hlthaff.26.4.950

[4] NRHM Mission Document (2005-2012). http://www.nird.org.in/brgf/doc/Rural\%20HealthMission_Document.pdf

[5] Selvaraj, S. (2011) A Critical Assessment of Existing Health Insurance Models in India. Planning Commission of India, New Delhi.

[6] Ahuja, R. (2004) Health Insurance for Poor. Economic and Political Weekly, 34, 3171-3178.

[7] Shiva, A.K., Chen, L.C., Mita, C., et al. (2011) Financing Health Care for All: Challenges and Opportunities. The Lancet, 377, 668-679. http://dx.doi.org/10.1016/S0140-6736(10)61884-3

[8] Garg, C. (1998) Equity of Health Sector Financing and Delivery in India: Harvard School of Public Health. http://citeseerx.ist.psu.edu/viewdoc/download?doi=10.1.1.202.5410\&rep=rep1\&type=pdf

[9] Peters, D., Yazbeck, A., Sharma, R., Ramana, G., Pritchett, L. and Wagstaff, A. (2002) Better Health Systems for India's Poor: Findings, Analysis and Options. The World Bank, Washington DC. http://dx.doi.org/10.1596/0-8213-5029-3

[10] Informal Sector in India: Approaches for Social Security. http://www.indg.in/social-sector/unorganised-labour/informal_sector_in_india_-_approaches_for_social_se curity.pdf/view

[11] Ministry of Statistics and Programme Implementation. http://mospi.nic.in/Mospi New/site/home.aspx

[12] Van Damme, W., Van Leemput, L., Por, I., Hardemann, W. and Meessen, B. (2004) Out-Of-Pocket Health Expenditure and Debt in Poor Households: Evidence from Cambodia. Tropical Medicine \& International Health, 9, $273-280$. http://dx.doi.org/10.1046/j.1365-3156.2003.01194.x

[13] Devadasan, N., Criel, B., Damme, W.V., Ranson, K. and Stuyft, P.V. (2007) Indian Community Health Insurance Schemes Provide Partial Protection against Catastrophic Health Expenditure. BMC Health Services Research, 7, 43. http://dx.doi.org/10.1186/1472-6963-7-43

[14] Mahal, A., Karan, A. and Engelau, M. (2010) The Economic Implications of Non-Communicable Disease for India. World Bank, Washington DC.

[15] Dong, H., Kouyate, B., Cairns, J. and Sauerborn, R. (2005) Inequality in Willingness-To-Pay for Community-Based Health Insurance. Health Policy, 72, 149-156. http://dx.doi.org/10.1016/j.healthpol.2004.02.014

[16] Preker, A., Carrin, G., et al. (2001) Role of Communities in Resource Mobilization and Risk Sharing: A Synthesis Report. World Health Organization, Geneva, 41.

[17] Benett, S. (2004) The Role of Community-Based Health Insurance within the Health Care Financing System: A Framework for Analysis. Health Policy and Planning, 19, 147-158. http://dx.doi.org/10.1093/heapol/czh018

[18] Sauerborn, R., Nougtara, A., Hien, M. and Diesfeld, H.J. (1996) Seasonal Variations of Household Costs of Illness in Burkina Faso. Social Science and Medicine, 43, 281-290. http://dx.doi.org/10.1016/0277-9536(95)00374-6

[19] Ranson, M.K. (2002) Reduction of Catastrophic Health Care Expenditures by a Community-Based Health Insurance Scheme in Gujarat, India: Current Experiences and Challenges. Bulletin of the World Health Organization, 80, 613621.

[20] Liu, Y. and Hsiao, W.C. (2003) For the People, by the People: Community Financing of Healthcare in Developing Countries. Harvard Health Policy Review, 4, 102-111.

[21] Allegri, M., Sanon, M. and Sauerborn, R. (2006) To Enroll or Not to Enroll? A Qualitative Investigation of Demand for Health Insurance in Rural West Africa. Social Science \& Medicine, 62, 1520-1527. http://dx.doi.org/10.1016/j.socscimed.2005.07.036

[22] Zeller, M. and Sharma, M. (1998) Rural Finance and Poverty Alleviation: Food Policy Report. International Food Policy Research Institute, Washington DC.

[23] Bennett, S., Creese, A. and Monasch, R. (1998) Health Insurance Schemes for People outside Formal Sector Employment. World Health Organization, Geneva.

[24] Bhat, R. and Jain, N. (2006) Factors Affecting the Demand for Health Insurance in a Micro Insurance Scheme. Working Paper No. 2006-07-02, India Institute of Management, Ahmadabad.

[25] Acharaya, A. and Ranson, M.K. (2005) Healthcare Financing for the Poor: Community Based Health Insurance Schemes in Gujarat. Economic and Political Weekly, 40, 4141-4150.

[26] Sinha, T., Ranson, K., Chatterjee, M., Acharya, A. and Mills, A. (2006) Barriers to Accessing Benefits in a Community-Based Health Insurance Scheme: Lessons Learnt from SEWA Insurance, Gujarat. Health Policy and Planning, 21, 132-142. http://dx.doi.org/10.1093/heapol/czj010 
[27] Mathiyazhagan, K. (1998) Willingness to Pay for Rural Health Insurance through Community Participation in India. The International Journal of Health Planning and Management, 13, 47-67. http://dx.doi.org/10.1002/(SICI)1099-1751(199801/03)13:1<47::AID-HPM495>3.0.CO;2-I

[28] Desai, S. (2009) Keeping the "Health” in Health Insurance. Economic and Political Weekly, XLIV, 18-21.

[29] Ranson, M.K., Sinha, T., Chatterjee, M., Gandhi, F., Jayswal, R., Patel, F., Morris, S.S. and Mills, A.J. (2007) Equitable Utilization of Indian Community Based Health Insurance Scheme among Its Rural Membership: Cluster Randomized Controlled Trial. British Medical Journal, 334, 1282-12783. http://dx.doi.org/10.1136/bmj.39192.719583.AE

[30] Bärnighausen, T., Liu, Y., Zhang, X. and Sauerborn, R. (2007) Willingness to Pay for Social Health Insurance among Informal Sector Workers in Wuhan, China: A Contingent Valuation Study. BMC Health Services Research, 7, 114. http://dx.doi.org/10.1186/1472-6963-7-114 